
licence (http://creativecommons.org/licenses/by-nc-nd/4.0/), which permits non-commercial re-use, distribution, and reproduction in any medium, provided the original work is unaltered and is properly cited. The written permission of Cambridge University Press must be obtained for commercial re-use or in order to create a derivative work.

\title{
Letter
}

\section{Comment on 'Mass gains of the Antarctic ice sheet exceed losses' by H. J. Zwally and others}

We have significant concerns with a study recently published in the Journal of Glaciology by Zwally and others (2015), hereafter 'Zwally 2015'. The paper concludes that the Antarctic ice-sheet mass is increasing, a result that is inconsistent with a large body of previously published work. No issue in the field of glaciology is currently more critical than the improvement of our understanding of ice mass balance for the major ice sheets and its consequent impact on sea level. This need for an improved understanding extends beyond the glaciological community and includes policy makers and the general public. For this reason, we feel that it is important to note here the evidence for problems with the methodologies used to arrive at the Zwally 2015 result.

The Zwally 2015 conclusion is clearly an outlier among recent studies of Antarctic mass balance. Combining satellite radar altimetry spanning 1992-2001 and satellite laser altimetry from 2003 to 2008, it purports to show that as of 2008, and for an extended period, net gains in Antarctic ice elevation - and therefore ice mass - have exceeded losses. Our analysis of the paper, presented below, reveals that the largest component of the signal leading to the positive mass balance is a surface elevation increase in the East Antarctic ice sheet (EAIS) interior, particularly for the Ice, Cloud, and land Elevation Satellite (ICESat) laser altimetry period. This is dependent upon $\mathrm{cm} \mathrm{a}^{-1}$ elevation change determinations using those satellite data.

Zwally 2015 report $+82 \pm 25 \mathrm{Gt} \mathrm{a}^{-1}$ for the ice sheet as a whole based on their ICESat data (2003-08), whereas the mean of eleven other studies published since 2012 for a similar period is approximately $-80+60 /-100 \mathrm{Gt} \mathrm{a}^{-1}$ (Fig. 1). No other recent assessment reports an unambiguous ice mass gain for the whole continent. The Ice Mass Balance Intercomparison Exercise (IMBIE) (Shepherd and others, 2012) was a reconciliation of nearly all highquality mass-balance estimates at that time, and included earlier results from the Zwally 2015 authors. That study reported an overall ice mass balance for the ICESat period of $-72 \pm 43 \mathrm{Gt} \mathrm{a}^{-1}$ for all of Antarctica, and $+58 \pm 31 \mathrm{Gt}$ $\mathrm{a}^{-1}$ for the EAIS alone. For comparison, in Zwally 2015 the mass balance for the EAIS is $+136 \pm 28 \mathrm{Gt} \mathrm{a}^{-1}, 2.3$ times the reconciled IMBIE value.

Zwally 2015 estimates a satellite-derived mean elevation rate change of $+1.3 \mathrm{~cm} \mathrm{a}^{-1}$ for the EAIS. One centimeter of elevation increase over the EAIS $\left(\sim 10\right.$ million $\left.\mathrm{km}^{2}\right)$ represents a mass gain of $92 \mathrm{Gt}$, if attributed to ice, and $\sim 35 \mathrm{Gt}$ if attributed to snow. Thus, if the Zwally 2015 elevation change is incorrect (too high) by just $+1 \mathrm{~cm} \mathrm{a}^{-1}$ for the EAIS, and is attributed to ice, the overall Antarctic ice mass gain they report is reversed, becoming $-10 \mathrm{Gt} \mathrm{a}^{-1}$. There is little evidence for recent change in annual snowfall in EAIS (e.g. Anschütz and others, 2011; Lenaerts and others, 2013). Therefore, Zwally 2015 infer that the thickening they detect across the EAIS interior is a consequence of accumulation increases that began at the end of the last ice age $(\sim 14 \mathrm{ka} B P)$ that have not yet equilibrated with the EAIS ice flow system. The proposed unequilibrated accumulation increase $\left(\sim 1 \mathrm{~cm}\right.$ ice eq. $\left.\mathrm{a}^{-1}\right)$ is $\sim 50 \%$ of the presentday accumulation for the EAIS interior. This implies that ice flow speed there today should be $\sim 50 \%$ of what would be expected in a balanced ice flow system. In fact, observed EAIS velocities are $\sim 80 \%$ of the balance velocities in recent estimates (van Wessem and others, 2014).

Zwally 2015 claim that the two data types they use (ERS-1 and -2, 1992-2001 and ICESat, 2003-08) show similar trends over the EAIS throughout the combined observing period (Zwally 2015, Figs 6, 7). However, few EAIS interior areas in their presented figure actually show similar trends. In the Subglacial Lake Vostok area, the trends appear similar, and their analysis indicates a rate of elevation gain of nearly 2 $\mathrm{cm} \mathrm{a}^{-1}$ for both datasets (their Fig. 7). However, for most of the EAIS interior (i.e. $>2000 \mathrm{~m}$ a.s.l. and north of $81.5^{\circ} \mathrm{S}$, the limit of radar altimetry coverage), the radar altimetryderived EAIS trend oscillates $\sim 0 \mathrm{~cm} \mathrm{a}^{-1}$, and is generally lower than the Zwally 2015 ICESat trend. South of $81.5^{\circ} \mathrm{S}$, Zwally 2015 use only the ICESat-based estimate, interpolated in space and time, increasing the dependence of the study's overall conclusions on their ICESat-based estimate.

If a product of post-glacial responses, the long-term thickening invoked by Zwally 2015 should continue to the present and beyond. However, recent data from the CryoSat-2 radar altimeter spanning 2010-13 (Helm and others, 2014; McMillan and others, 2015) show very small elevation changes for the EAIS interior, $\sim 0 \pm 1 \mathrm{~cm} \mathrm{a}^{-1}$. Helm and others (2014) indicate a mean elevation change for EAIS of only $+0.6 \mathrm{~cm} \mathrm{a}^{-1} \pm<1 \mathrm{~cm} \mathrm{a}^{-1}$ based on their volume change result of $+59 \pm 63 \mathrm{~km}^{3} \mathrm{a}^{-1}$. McMillian and others directly report a mean elevation change of $+0.1 \pm 0.2 \mathrm{~cm}$ $\mathrm{a}^{-1}$ and a mass balance of $-3 \pm 36 \mathrm{Gt}^{-1}$ for EAIS. In both studies, the CryoSat-2-derived elevation change rates imply a far smaller overall EAIS mass change, even if attributed entirely to ice as asserted by Zwally 2015.

In diagnosing where the underlying issue in Zwally 2015 might be, we note that there are two main contributions to their strong positive EAIS mass trend from ICESat: (1) ICESat's Geoscience Laser Altimeter System's (GLAS) detector saturation and its residual effects after applying standard corrections to the data, and (2) the use of an unconventional method to estimate documented biases between the ICESat data collection campaigns.

\section{DETECTOR SATURATION}

Saturation of the GLAS detectors occurred when the transmitted laser energy was high, the reflecting surface had a high albedo, and/or the atmosphere was very clear. This effect broadened the laser return pulse, producing a truncated peak and an extended trailing edge (Fricker and others, 2005; Sun and others, 2005). Since the altimeter range for each pulse was determined by fitting a Gaussian curve to the return waveform, the truncated peak and extended tail 
pushed the Gaussian peak later in time, anomalously increasing the range from the satellite to the surface (i.e. lowering the recovered elevation). Laser energy declined during the lifetime of each GLAS laser, reducing the number of saturation-impacted returns in later campaigns. The last ICESat campaigns in 2008 and 2009 had very low transmit energies. If the derived variations in elevation due to detector saturation were not (or not fully) corrected, a bright surface would exhibit an apparent, but incorrect, increase in elevation through time as laser energy and saturation decreased through each GLAS laser's lifetime assuming consistent mean albedo and atmospheric conditions. Saturation effects were particularly prevalent on the EAIS due to its clear polar atmosphere, high elevation, and bright, dry snow surface.

The serious issue with saturation was noted early in the ICESat mission. Laboratory measurements using spare GLAS receiver components were used to determine the range bias due to saturation as a function of received energy and detector gain (Sun and others, 2005). This was initially validated by a comparison of raw and corrected ICESat profiles with GPS ground survey data at the salar de Uyuni in Bolivia, a bright, flat high-altitude playa (Fricker and others, 2005). Late in the mission, a modified saturation correction algorithm with larger values was subsequently developed and applied only to Laser 3 data in Release 33 (Past Release notes, NSIDC, 2013). However, significant residual effects remain over the mission lifetime after correcting for saturation, which could cause an apparent $\mathrm{cm} \mathrm{a}^{-1}$ level increase in surface elevation (Gunter and others, 2009; Schutz and others, 2011; Shuman and others, 2011; Urban and others, 2013). Thus, for saturation-impacted surfaces such as the EAIS plateau, ICESat-derived trends can show a net apparent increase in elevation over time, unless this is assessed and removed by using some independently constrained area of the ice sheet itself or a very similar surface to compensate for performance variations between the laser altimetry campaigns.

\section{INTERCAMPAIGN (IC) BIASES}

IC bias corrections are adjustments applied to the elevation data from ICESat campaigns, so that an unchanging elevation surface, or a surface for which the rate of change is well known, shows the near-zero or known elevation change through the ICESat campaign series. Several studies have determined bias corrections by various means based on different reference targets, including the global ocean (e.g. Gunter and others, 2009; Urban and others, 2013), central Greenland (Siegfried and others, 2011) and East Antarctica (e.g. Hofton and others, 2013; Richter and others, 2014). We limit our comparisons here to recent assessments (Shepherd and others, 2012; Hofton and others, 2013; Urban and others, 2013; Gunter and others, 2014; Helm and others, 2014), most of which have incorporated a small correction factor for how the range is measured, which was recognized in late 2012 ('the Gaussian minus Centroid (G-C) correction'; Borsa and others, 2014). Note that the $\mathrm{G}-\mathrm{C}$ correction, if not applied, will be included as part of IC-bias estimates, and will have little net impact for statistically large ICESat datasets, as Helm and others (2014) and Zwally 2015 note. Our review shows that the IC-bias corrections used by Zwally 2015 are very different relative to the other assessments of IC bias (Table 1; Fig. 2).

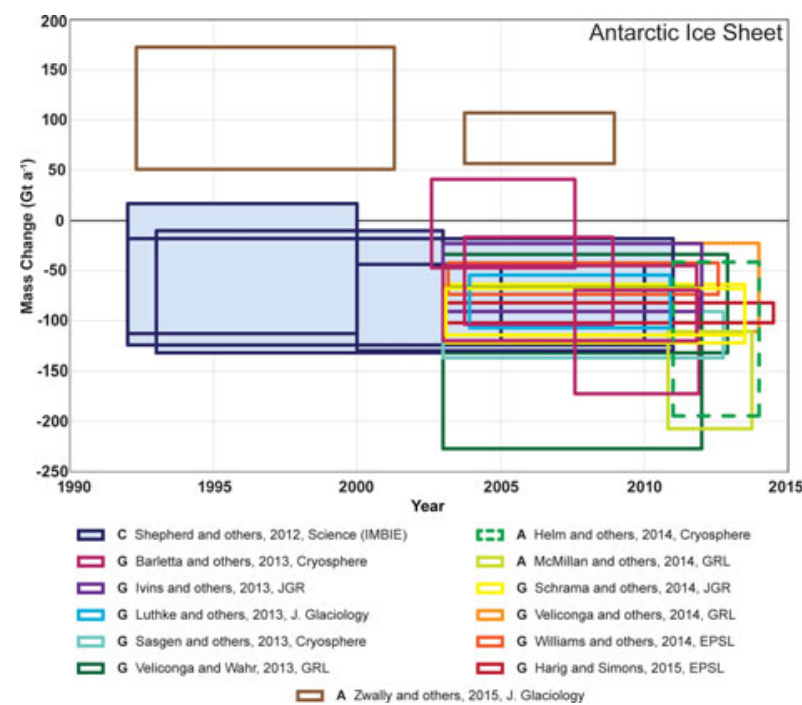

Fig. 1. Recent mass-balance estimates for the Antarctic ice sheet (L. Trusel, personal communication, December 2015). The box areas represent the error range (vertical) and the period spanned by the estimates. The citations for each estimate and the type of estimate are given in the key: $\mathrm{C}$ for consensus; $\mathrm{G}$ for gravity-based; $\mathrm{A}$ for altimetry-based. For the Helm and others (2014) study, only volume was calculated, so we converted their Antarctic volume change assessment to mass using the density of ice $\left(917 \mathrm{~kg} \mathrm{~m}^{-3}\right)$.

Zwally 2015 derived their IC-bias correction values from Arctic and Antarctic Ocean surfaces between sea-ice floes, i.e. within leads and polynyas. This approach largely eliminates any impact of wave-related roughness (Kwok and others, 2007; Zwally and others, 2008). While this method is adequate for estimating sea-ice freeboard, polar oceans are not a good reference surface analog for ice-sheet areas, since they are comparatively dark and rarely have saturated returns. In addition, a review of the method (Kern and Spreen, 2015) attributes significant $(\sim 4 \mathrm{~cm})$ errors to the determination of sea surface height from this method, depending sensitively upon the filtering parameters applied to ICESat profiles acquired over polar oceans. The Zwally 2015 bias corrections derived from this approach (' $D$ ' values) impart a $-0.48 \mathrm{~cm} \mathrm{a}^{-1}$ slope through the ICESat 2003-08 portion of the mission. These are further adjusted in Zwally 2015 by comparison with contemporaneous Envisat measurements of sea surface height. This second adjustment is an attempt to account for effects of seasonal dynamic ocean topography and the sea-level effects of any coastal ice-sheet mass loss. Indeed, loss of such coastal ice mass reduces the gravitational pull on the adjacent ocean and therefore causes broad areas of significant local sea-level decline in the polar regions. However, due to the large pulse-limited footprint of Envisat's radar altimeter, the derived Envisat adjustment data are even more likely than the ICESat data to be impacted by sea-ice floes adjacent to the leads. Over the course of the ICESat mission, Arctic sea ice has exhibited a very strong thinning trend, and this may have affected the Envisatderived sea-level adjustment. The total biases $\left(D_{\mathrm{SL}}\right)$ have a $-1.43 \mathrm{~cm} \mathrm{a}^{-1}$ slope through the 2003-08 ICESat campaign series. Applying the $D_{\mathrm{SL}}$ bias estimate effectively adds almost $+1.5 \mathrm{~cm} \mathrm{a}^{-1}$ to any ice-sheet elevation trend derived from ICESat with this approach. Thus, the combination of both residual GLAS detector saturation effects and the Zwally 2015 imposed polar-ocean-based bias 
Table 1. Published ICESat Intercampaign Bias Assessments

\begin{tabular}{|c|c|c|c|c|c|c|c|c|}
\hline \multirow[b]{2}{*}{ ICESat campaign } & \multicolumn{2}{|c|}{ Hofton and others (2013) } & \multirow{2}{*}{$\begin{array}{l}\text { Helm and } \\
\text { others }(2014)^{*}+\end{array}$} & \multirow{2}{*}{$\begin{array}{c}\begin{array}{l}\text { Gunter and } \\
\text { others }(2014)^{*}\end{array} \\
\text { (EA LPZ) }\end{array}$} & \multirow{2}{*}{$\begin{array}{l}\text { Shepherd and } \\
\text { others }(2012)^{*}\end{array}$} & \multirow{2}{*}{$\begin{array}{l}\begin{array}{l}\text { Urban and } \\
\text { others }(2013) \neq\end{array} \\
\text { (Ocean) }\end{array}$} & \multicolumn{2}{|c|}{$\begin{array}{l}\text { Zwally and } \\
\text { others (2015)§ }\end{array}$} \\
\hline & (86 ${ }^{\circ} \mathrm{S}$ orbit ring) & (EA Divide) & & & & & $D_{\mathrm{SL}}$ & $D$ \\
\hline L1A & $-1.14 \pm 1.63$ & $-5.08 \pm 5.52$ & -8.30 & $-5.80 \pm 1.7$ & - & $-4.7 \pm 3.6$ & - & - \\
\hline L2A & $+3.22 \pm 1.84$ & $+0.41 \pm 5.46$ & -7.40 & $-6.90 \pm 1.5$ & $-5.1 \pm 1.4$ & $+4.8 \pm 1.3$ & +4.60 & -3.90 \\
\hline L2B & $-1.03 \pm 4.27$ & $-1.56 \pm 4.28$ & -5.30 & $-5.00 \pm 1.7$ & $-3.6 \pm 1.4$ & $+0.5 \pm 1.3$ & +10.40 & +0.90 \\
\hline L2C & $+7.09 \pm 5.48$ & $+2.39 \pm 5.65$ & +2.70 & $-1.60 \pm 4.7$ & $2.1 \pm 5.3$ & $+4.1 \pm 0.9$ & +11.40 & +0.10 \\
\hline L3A & $-2.66 \pm 4.00$ & $-6.73 \pm 3.88$ & -6.60 & $-6.50 \pm 3.4$ & $-2.4 \pm 0.9$ & $+1.0 \pm 1.3$ & +5.70 & -2.40 \\
\hline L3B & $-2.46 \pm 3.08$ & $-5.10 \pm 4.59$ & -6.90 & $-4.70 \pm 2.3$ & $-2.1 \pm 1.1$ & $+0.2 \pm 1.1$ & +3.40 & -7.40 \\
\hline L3C & $-3.55 \pm 3.85$ & $-6.20 \pm 4.69$ & -4.30 & $-3.10 \pm 2.4$ & $+1.1 \pm 1.5$ & $+1.0 \pm 1.5$ & +6.30 & -1.30 \\
\hline L3D & $+1.60 \pm 2.53$ & $-3.22 \pm 4.22$ & +0.60 & $-0.40 \pm 2.0$ & $+0.8 \pm 0.9$ & $+0.4 \pm 1.0$ & +0.30 & -5.30 \\
\hline L3E & $+1.75 \pm 1.64$ & $-1.12 \pm 4.45$ & -1.00 & $-0.30 \pm 1.3$ & $+0.8 \pm 0.7$ & $+0.3 \pm 0.7$ & +3.90 & -3.00 \\
\hline L3F & $-2.18 \pm 2.26$ & $-4.85 \pm 4.91$ & -2.50 & $-1.40 \pm 2.6$ & $+0.0 \pm 1.1$ & $+0.1 \pm 0.9$ & +1.20 & -5.60 \\
\hline L3G & $+3.21 \pm 0.82$ & $-1.12 \pm 4.91$ & +2.50 & $+0.80 \pm 1.4$ & $+2.1 \pm 0.7$ & $+1.9 \pm 0.7$ & +0.30 & -3.20 \\
\hline L3H & $+1.16 \pm 1.81$ & $+0.07 \pm 3.03$ & -1.30 & $+0.30 \pm 1.0$ & $+1.5 \pm 0.9$ & $+1.2 \pm 0.9$ & +5.40 & -2.00 \\
\hline L3I & $0.00 \pm 3.20$ & $0.00 \pm 3.30$ & 0.00 & $0.00 \pm 1.4$ & $0.0 \pm 0.9$ & $0.0 \pm 0.9$ & 0.00 & 0.00 \\
\hline L3] & $+3.45 \pm 2.31$ & $+1.33 \pm 5.24$ & +3.20 & $+1.90 \pm 1.3$ & $-1.0 \pm 1.3$ & $-1.2 \pm 1.4$ & +1.00 & -2.60 \\
\hline L3K & $+6.23 \pm 2.59$ & $+3.14 \pm 3.40$ & +4.50 & $+3.10 \pm 2.9$ & $-0.2 \pm 1.4$ & $-0.7 \pm 2.0$ & +1.80 & -6.10 \\
\hline L2D & $+7.71 \pm 1.51$ & $+7.29 \pm 4.46$ & +0.90 & $+1.70 \pm 2.5$ & $+1.8 \pm 1.8$ & $+5.7 \pm 1.7$ & +1.80 & -6.10 \\
\hline L2E & $+14.72 \pm 3.03$ & $+13.93 \pm 4.89$ & +1.80 & $+3.30 \pm 5.6$ & $+5.3 \pm 4.4$ & $+11.2 \pm 7.3$ & - & - \\
\hline $\mathrm{L} 2 \mathrm{~F}$ & $+7.43 \pm 2.84$ & $+4.21 \pm 4.35$ & +1.40 & $+2.50 \pm 5.5$ & $-1.2 \pm 1.3$ & $+4.9 \pm 1.2$ & - & - \\
\hline
\end{tabular}

All values in $\mathrm{cm}$. All published IC biases presented here have been adjusted to be relative to the Laser $3 \mathrm{I}$ campaign (zero). Uncertainties ( \pm ) are included if available. Bold text in the first column indicates the campaigns that are used in Zwally and others (2015) for their IC bias and related mass-balance assessments. Studies with additional campaigns all have positive IC bias trends.

* These data were based on Release 633 data so did not have the Gaussian minus Centroid $(\mathrm{G}-\mathrm{C})$ correction applied. All other analyses were updated to include this correction. See the original references for additional details. The IMBIE bias numbers have had a $0.3 \mathrm{~cm} \mathrm{a}^{-1}$ sea level increase removed as in Hofton and others (2013).

+ Ewert and others (2012) was updated for Helm and others (2014) and then also for Richter and others (2014) by including the G-C correction (see their Table 3, $\Delta H_{\mathrm{GC}}$ column). They also examined the early Laser $2 \mathrm{~A}$ data separately when ICESat was in an 8-day repeat orbit but this data was not used here.

\# These bias numbers have been updated by Urban, personal communication (2015).

$\S$ From Zwally and others (2015), $D_{\text {SL }}$ equals the $D$ value plus an Envisat-derived correction for sea level variations.

corrections will increase the elevation trend of an otherwise stationary, high-albedo ice-sheet surface such as EAIS.

\section{INDEPENDENT ESTIMATES}

To further evaluate the Zwally 2015 results, we compiled independent assessments of the surface elevation change in the EAIS. As already discussed, data from CryoSat-2 show + $0.6 \pm<1 \mathrm{~cm} \mathrm{a}^{-1}$ (Helm and others, 2014) or $+0.1 \pm 0.2$ $\mathrm{cm} \mathrm{a}^{-1}$ (McMillan and others, 2015), and ERS-1 and -2 data in the EAIS interior generally oscillate $\sim 0 \mathrm{~cm} \mathrm{a}^{-1}$ in the early part of the study period (Zwally 2015, their Fig. 6a). Collectively, these radar altimetry studies do not support prolonged ice mass accumulation.

There is an in situ assessment of surface elevation change for the Subglacial Lake Vostok region, discussed in a series of papers by Richter and others (2008, 2013, 2014). Richter and others (2014, this volume) used repeated GPS measurements and reported a net rate of change of $0.1 \pm 0.5 \mathrm{~cm} \mathrm{a}^{-1}$ over an 11 a period spanning the full 2003-09 ICESat mission. In contrast, Zwally 2015 derives a $+2.0 \mathrm{~cm} \mathrm{a}^{-1}$ elevation increase in this region for their combined 1992-2008 altimetry record (their Fig. 7). Richter and others (2014, their Fig. 2 and associated text) document that their study was aware of all significant potential impacts on the in situ elevation change measurements. Effectively, Zwally 2015 imply that the Richter and others $(2008,2014)$ studies did not detect a $\sim 20 \mathrm{~cm}$ total rise between their earliest and latest measurements.

In refuting the Richter and others studies (see Zwally 2015 Appendix), Zwally 2015 arbitrarily suggests that a better specific density for new snow might be 0.30 , rather than 0.33 as used by Richter and others (2014), despite numerous snow pit density measurements (Ekaykin and others, 2004). Zwally 2015 similarly invokes a variety of other estimates of accumulation rate, rather than accept the results of Ekaykin and others (2004) who acquired data in the immediate vicinity of the stake grid, using a combination of shallow ice cores and snow pits. The accumulation values suggested by Zwally 2015 are generally higher, implying that the in situ data collection in the Vostok area might be in error by $>20 \mathrm{~cm}$.

Further, as presented by Ewert and others (2012), Subglacial Lake Vostok is in hydrostatic equilibrium, at least in its central ice surface area. This means that any valid ice-driven elevation change seen in the surrounding EAIS region should be reduced to $\sim 1 / 12$ the grounded-ice rate over the lake surface. Zwally 2015 highlights the data over the Vostok region but show no discernable difference in elevation change rate from the grounded ice to the lake surface. The uniformity of their ICESat-determined elevation change strongly implies that their results are affected by some kind of measurement bias unrelated to real ice-sheet thickening.

\section{SUMMARY}

An assessment of the array of studies reviewed here regarding EAIS elevation changes can take one of two paths. If we accept the net IC-bias corrections of Zwally 2015 and their subsequent elevation change results, then we must assume: (1) that two CryoSat-2 studies of EAIS elevation changes have errors of three to ten times their stated uncertainties; 


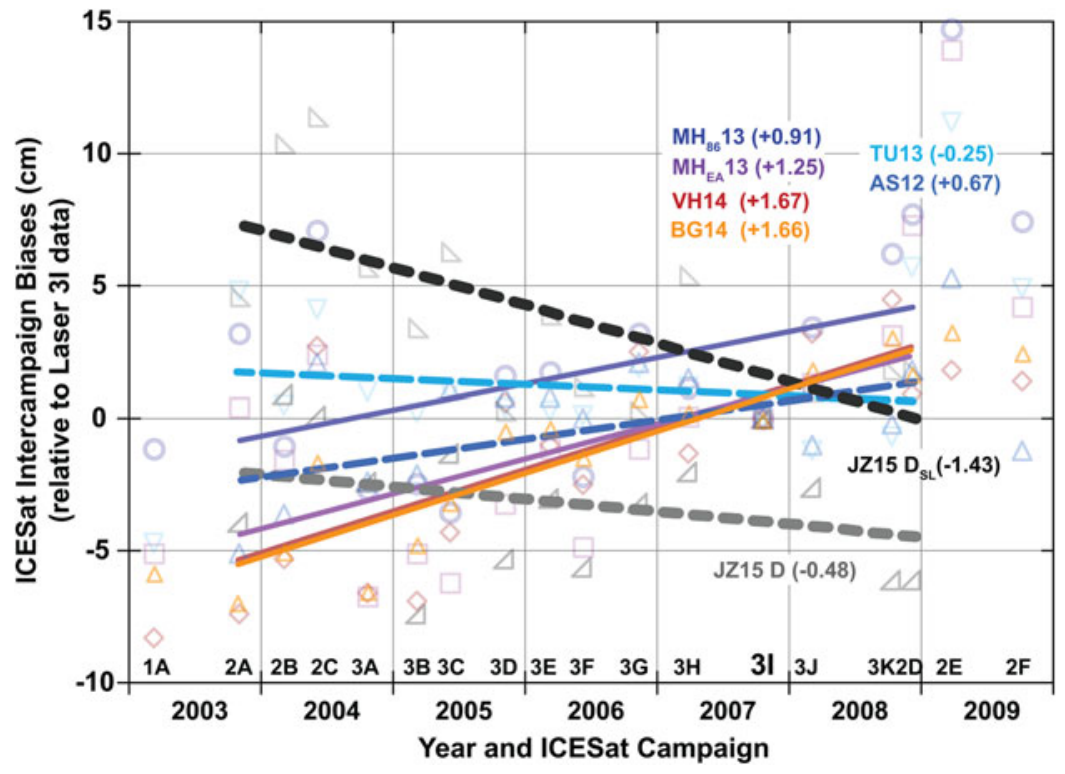

Fig. 2. IC bias estimates from several recent studies (symbols) and the regression trends they impart to the 2003-08 portion of the data series (lines). Symbols are color-coded to the different analyses and reference regions: "JZ15 D" (Zwally 2015, D series), grey right-corner triangles;

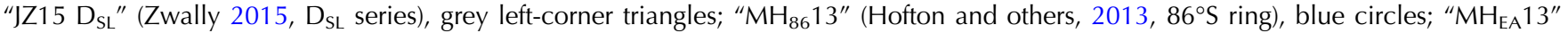
(Hofton and others, 2013, East Antarctic divide), purple squares; "VH14" (Helm and others, 2014, Vostok area; modified from Ewert and others, 2012), red diamonds; "BG14" (Gunter and others, 2014, East Antarctic low precipitation zone), orange up-pointing triangles, "TU13" (Urban and others, 2013, global ocean) down-pointing blue triangles; and "AS12" (Shepherd and others, 2012, global ocean), uppointing blue triangles.

(2) that all other studies of recent Antarctic mass balance (Fig. 1) are in error; (3) that EAIS balance velocities based on accumulation models, which currently approximate observed velocities well, are wrong by a large margin; (4) that field studies dedicated to the determination of surface height change over the Subglacial Lake Vostok area did not detect $\sim 20 \mathrm{~cm}$ (or greater) increases between 2001 and 2013 (4 $\times$ their reported uncertainty); (5) that the assessment of subglacial lake hydrostatic equilibrium is in error; (6) that all other studies of IC-biases are wrong by a considerable margin. However, if instead, we assume that the combined corrections used by Zwally 2015 are invalid - if they are replaced with any of the other IC-bias determinations, then: (1) the elevation trend for the EAIS interior is near zero; (2) Antarctic ice-sheet mass gains do not exceed losses; (3) the field studies conducted at Subglacial Lake Vostok are accurate; (4) the CryoSat-2 studies and other recent Antarctic ice mass-balance studies are consistent. The other IC-bias assessments are also relatively self-consistent, and the differences among them (especially ocean-based versus EAIS-based) may be interpreted to be due to residual GLAS measurement uncertainties (e.g. uncompensated saturation effects) when the reference surface is bright snow versus dark ocean.

One positive outcome of this analysis is that the Subglacial Lake Vostok surface, in fact, offers what may be the best possible reference surface for future altimetry assessments of icesheet elevation change. As a floating ice surface with low or no ongoing thickening, its rate of change must be a tiny fraction of any EAIS elevation change. In assessing overall icesheet elevation and mass changes, especially in East Antarctica, centimeters matter, and the reference surface needs to be as similar in character to the EAIS surface as possible. Subglacial Lake Vostok presents better reference characteristics for ice-sheet surfaces than other sites, a consideration for future ICESat assessments and future laser altimetry missions such as ICESat-2.

The following is a partial list of web pages offering initial responses to the Zwally 2015 study:

http://www.realclimate.org/index.php/archives/2015/11/sowhat-is-really-happening-in-antarctica/

https://ourchangingclimate.wordpress.com/2015/11/25/antarctica-ice-gain-or-loss/

http://climatecrocks.com/2015/11/03/more-on-antarctic-icemelt/

http://www.carbonbrief.org/qa-is-antarctica-gaining-orlosing-ice/

\section{ACKNOWLEDGEMENTS}

We appreciate the comments of two anonymous reviewers, as well as other useful comments and additional insights provided by L. Trusel of Woods Hole Oceanographic Institution (who composed Fig. 1), E. Berthier of the University of Toulouse, B. Csatho of the University of Buffalo and M. Hofton of the University of Maryland.

${ }^{1}$ National Snow and Ice Data Center,

T. SCAMBOS ${ }^{1}$

University of Colorado, Boulder,

C. SHUMAN ${ }^{23}$

${ }^{2}$ Joint Center for Earth Systems

Technology, University of Maryland,

Baltimore County 21250, USA

${ }^{3}$ NASA Goddard Space Flight Center, Greenbelt, Maryland 20771, USA

E-mail: teds@nsidc.org 


\section{REFERENCES}

Anschütz $\mathrm{H}$ and 8 others (2011) Variation of accumulation rates over the last eight centuries on the East Antarctic Plateau derived from volcanic signals in ice cores. J. Geophys. Res.: Atmosph. (19842012), 116(D20) (doi: 10.1029/2011JD015753)

Barletta VR, Sørensen LS and Forsberg R (2013) Scatter of mass changes estimates at basin scale for Greenland and Antarctica Cryosphere, 7(5), 1411-1432 (doi: 10.5194/tc-7-1411-2013)

Borsa AA, Moholdt G, Fricker HA and Brunt KM (2014) A range correction for ICESat and its potential impact on ice-sheet mass balance studies. Cryosphere, 8, 345-357 (doi: 10.5194/tc-8-345-2014)

Ekaykin A and 5 others (2004) The changes in isotope composition and accumulation of snow at Vostok station, East Antarctica, over the past 200 years. Ann. Glaciol., 39, 569-575 (doi: 10.3189/ $172756404781814348)$

Ewert $\mathrm{H}$ and 5 others (2012) Precise analysis of ICESat altimetry data and assessment of the hydrostatic equilibrium for subglacial Lake Vostok, East Antarctica. Geophys. J. Int., 191, 557-568 (doi: 10.1111/j.1365-246X.2012.05649.x)

Fricker HA and 5 others (2005) Assessment of ICESat performance in the Salar de Uyuni, Bolivia. Geophys. Res. Lett., 32, L21S06 (doi: 10.0129/2005GL023423)

Gunter B and 8 others (2009) A comparison of coincident GRACE and ICESat data over Antarctica. J. Geodesy, 83(11), 10511060 (doi: 10.1007/s00190-009-0323-4)

Gunter BC and 7 others (2014) Empirical estimation of present-day Antarctic glacial isostatic adjustment and ice mass change. Cryosphere, 8, 743-760 (doi: 10.5194/tc-8-743-2014)

Harig C and Simons FJ (2015) Accelerated West Antarctic ice mass loss continues to outpace East Antarctic gains. Earth Planet. Sci. Lett., 415, 134-141 (doi: 10.1016/j.epsl.2015.01.029)

Helm V, Humbert A and Miller H (2014) Elevation and elevation change of Greenland and Antarctica derived from CryoSat-2. Cryosphere, 8, 1539-1559 (doi: 10.5194/tc-8-1539-2014)

Hofton MA, Luthcke SB and Blair JB (2013) Estimation of ICESat intercampaign elevation biases from comparison of lidar data in East Antarctica. Geophys. Res. Lett., 40, 5698-5703 (doi: 10.1002/2013GL057652)

Ivins ER and 6 others (2013) Antarctic contribution to sea level rise observed by GRACE with improved GIA correction. J. Geophys. Res. Solid Earth, 118(6), 3126-3141 (doi: 10.1002/jgrb.50208)

Kern S and Spreen G (2015) Uncertainties in Antarctic sea-ice thickness retrieval from ICESat. Ann. Glaciol., 56(69), 107-119 (doi: 10.3189/2015AoG69A736)

Kwok R, Cunningham GF, Zwally HJ and Yi D (2007) Ice, Cloud and land Elevation Satellite (ICESat) over Arctic sea ice: retrieval of freeboard. J. Geophys. Res., 112, C12013 (doi: 10.1029/ 2006JC0003978)

Lenaerts JTM and 5 others (2013) Recent snowfall anomalies in Dronning Maud Land, East Antarctica, in a historical and future climate perspective. Geophys. Res. Lett., 40, 2684-2688 (doi: 10.1002/grl.50559)

Luthcke SB and 5 others (2013) Antarctica, Greenland and Gulf of Alaska land-ice evolution from an iterated GRACE global mascon solution. J. Glaciol., 59(216), 613-631 (doi: 10.3189/2013JoG12J147)

McMillan M and 7 others (2015) Increased ice losses from Antarctica detected by CryoSat-2. Geophys. Res. Lett., 41, 3899-3905 (doi: 10.1002/2014GL060111)

NSIDC (2013) https://nsidc.org/data/icesat/past_releases.html\#rel33alt-bin.

Richter A and 9 others (2008) Observational evidence on the stability of the hydro-glaciological regime of subglacial Lake Vostok. Geophys. Res. Lett., 35(11)

Richter A and 10 others (2013) Ice flow velocities over Vostok Subglacial Lake, East Antarctica, determined by 10 years of GNSS observations. J. Glaciol., 59(214), 315-326 (doi: 10.3189/ 2103JoG12J056)
Richter A and 12 others (2014) Height changes over subglacial Lake Vostok, East Antarctica: insights from GNSS observations. J. Geophys. Res. Earth Surf., 119, 2460-2480 (doi: 10.1002/ 2014JF003228)

Sasgen I and 6 others (2013) Antarctic ice-mass balance 2003 to 2012: regional reanalysis of GRACE satellite gravimetry measurements with improved estimate of glacial-isostatic adjustment based on GPS uplift rates. Cryosphere, 7, 1499-1512 (doi: 10.5194/tc-7-1499-2013)

Schrama E, Wouters B and Rietbroek R (2014) A mascon approach to assess ice sheet and glacier mass balances and their uncertainties from GRACE data. J. Geophys. Res. Solid Earth, 119(7), 6048-6066 (doi: 10.1002/2013JB010923)

Schutz BE, Zwally HJ, Shuman CA, Hancock D and DiMarzio JP (2005) Overview of the ICESat Mission. Geophys. Res. Lett., 32, L21S01 (doi: 10.1029/2005GL024009)

Schutz R, DiMarzio J, Luthcke S, Hancock D and Urban T (2011) Notice concerning detection of ICESat inter-campaign elevation biases. https://nsidc.org/sites/nsidc.org/files/files/inter-campaign_ bias_notice_v1.pdf.

Shepherd A and 45 others (2012) A reconciled estimate of ice-sheet mass balance. Science, 338, 1183-1189 (doi: 10.1126/ science.1228102)

Shuman C, Harding D, Cornejo H and Suchdeo V (2011) Assessment of range bias in the ICESat (2003-2009) elevation time series and elevation changes at large subglacial lake sites, Antarctica. Geophys. Res. Abstr., 13, EGU2011-9259

Siegfried MR, Hawley RL and Burkhart JF (2011) High-resolution ground-based GPS measurements show intercampaign bias in ICESat elevation data near Summit, Greenland. IEEE Trans. Geosci. Remt. Sens., 49(9), 3393-3400 (doi: 10.1109/ TGRS.2011.2127483)

Sun XJB, Abshire JB, Yi D and Fricker HA (2005) ICESat receiver signal dynamic range assessment and correction of range bias due to saturation. EOS Trans. AGU, 86, 2005 Fall Meet. Suppl., Abstract C234A-07

Urban T and Schutz B (2005) ICESat sea level comparisons. Geophys. Res. Lett., 32 (doi: 10.1029/2005GL024306)

Urban T and 12 others (2012) Summary of ICESat-1 inter-campaign elevation biases and detection methods. EOS Trans. AGU, Fall Meet. Suppl., Abstract C13H-03

Urban T, Pie N, Felikson D and Schutz BE (2013) Impacts on Greenland and Antarctica ice sheet mass balance from estimation of ICESat-1/ GLAS inter-campaign elevation biases over the oceans. EOS Trans. AGU, Fall Meet. Suppl., Abstract C21D-0660

van Wessem JM and 10 others (2014) Improved representation of East Antarctic surface mass balance in a regional atmospheric climate model. J. Glaciol., 60(222), 761-770 (doi: 10.3189/ 2014JoG14J051)

Velicogna I and Wahr J (2013) Time-variable gravity observations of ice sheet mass balance: precision and limitations of the GRACE satellite data. Geophys. Res. Lett., 40(12), 3055-3063 (doi: 10.1002/grl.50527)

Velicogna I, Sutterley T and van den Broeke MR (2014) Regional acceleration in ice mass loss from Greenland and Antarctica using GRACE time-variable gravity data. Geoplys. Res. Lett., 41(22), 8130-8137

Williams S, Moore P, King MA and Whitehouse P (2014) Revisiting GRACE Antarctic ice mass trends and accelerations considering autocorrelation. Earth Planet. Sci. Lett., 385, 12-21 (doi: 10.1016/j.epsl.2013.10.016)

Zwally HJ, Yi D, Kwok R and Zhao Y (2008) ICESat measurements of sea ice freeboard and estimates of sea ice thickness in the Weddell Sea. J. Geophys. Res., 113(C2), C02S15 (doi: 10.1029/2007JC004284)

Zwally HJ and 5 others (2015) Mass gains of the Antarctic ice sheet exceed losses. J. Glaciol., 61(230), 1019-1035 (doi: 10.3189/ 2015JoG15J071) 